\title{
Knowledge and Attitude of Diabetes Mellitus Type 2 among Health Sciences Students In Uitm Puncak Alam, Selangor.
}

\author{
Roslinda Isa, Nur Adzirah Abd Rahman, Nur Aida Zainal Abidin, Zetty Idlia Idris \\ Centre of Nursing Studies, Faculty of Health Sciences, \\ Universiti Teknologi MARA, Cawangan Selangor Kampus Puncak Alam, 42300 Kuala Selangor, Selangor, Malaysia. \\ roslindaisa@uitm.edu.my, adzirah.rahman97@gmail.com ,nuraidazainal96@gmail.com, zttyy97@gmail.com \\ Tel: $011-21826220$
}

\begin{abstract}
Poorly controlled diabetes among young people poses a significant challenge to public health in the future since it will be affecting the economy and become a social burden. Health sciences students should have a good knowledge of diabetic Mellitus (DM) management since they play an important role in patient education. This study aims to assess the level of knowledge and attitude of DM Type 2 among health sciences students. A cross-sectional study using DKQ-24 and Attitude towards Diabetes Mellitus Questionnaire were used. More than half of the respondents scored moderate and good knowledge with $50 \%$ displaying a positive attitude and proven statistically significant.
\end{abstract}

Keywords: Diabetes Mellitus; knowledge; attitude; students

eISSN: 2398-4287@ 2020. The Authors. Published for AMER ABRA CE-Bs by e-International Publishing House, Ltd., UK. This is an open access article under the CC BYNC-ND license (http://creativecommons.org/licenses/by-nc-nd/4.0/. Peer-review under responsibility of AMER (Association of Malaysian Environment-Behaviour Researchers), ABRA (Association of Behavioural Researchers on Asians) and cE-Bs (Centre for Environment-Behaviour Studies), Faculty of Architecture, Planning \& Surveying, Universiti Teknologi MARA, Malaysia.

DOI: https://doi.org/10.21834/ebpj.v5i15.2464

\subsection{Introduction}

Diabetes Mellitus is a condition when the pancreas does not produce sufficient insulin or impaired ability to use insulin effectively. Without insulin, the body unable to use or store glucose for energy. Thus, glucose remains in the blood (Cotton, 2019). For adults aged 18 years and over, the prevalence of diabetes in Malaysia was $15.2 \%$ diabetes in which $7.2 \%$ are confirmed to be diabetic and $8 \%$ are previously undiagnosed (Suzana, Jamaludin, Noor Safiza et al., 2012). With rising diabetes prevalence, more young adults and teenagers are developing diabetes (Dabelea, DeGroat, Sorrelman et al., 2009). Mongiello, Freudenberg, Jones et al. (2016) stated that students in college develop a long-term diet and health behaviors associated with the increased lifetime risk of Diabetes Mellitus Type 2 since many university students underestimate the risk of diabetes. University students are at greater risk to develop diabetes mellitus because of a lack of physical activity, high BMI, poor knowledge about the disease, and an increased history of diabetes in their families (Khan, Gomati, Shehnaz et al., 2012).

Awareness can be seen by the respondents about diabetes mellitus, but knowledge level related to causes, risk factors, and complications about diabetes were poor (Mgbahurike, Onwusah, \& Amadi, 2017). A less satisfactory result was observed in a study done among nursing students where the respondents have poor knowledge in managing patients with diabetes including the diet and symptoms of diabetes (Shilpashree \& Namita, 2018). A study in Malaysia found that the awareness of Malaysian people, especially among the younger generation towards the complications of Diabetic Mellitus such as neuropathy, retinopathy, albuminuria, and microalbuminuria is still inadequate (Premkumar, 2018). The prevalence of diabetes type 2 is growing globally and represents a

eISSN: 2398-4287C 2020. The Authors. Published for AMER ABRA cE-Bs by e-International Publishing House, Ltd., UK. This is an open access article under the CC BYNC-ND license (http://creativecommons.org/licenses/by-nc-nd/4.0/). Peer-review under responsibility of AMER (Association of Malaysian Environment-Behaviour Researchers), ABRA (Association of Behavioural Researchers on Asians) and cE-Bs (Centre for Environment-Behaviour Studies), Faculty of Architecture, Planning \& Surveying, Universiti Teknologi MARA, Malaysia.

DOI: https://doi.org/10.21834/ebpj.v5i15.2464 
significant burden on public health and socio-economic development of all nations (Begic, Arnoutovic \& Masic, 2016). Porojan, Poantă, and Dumitraşcu (2012) report that diabetic Mellitus put a substantial burden on affected individuals by influencing physical, psychological, and social aspects of quality of life. Besides that, a collaborative care adaptation that involves the physicians, pharmacists, and nurses should play their part in offering the community diabetes education (Qamar, Rashid, Ahmad et al., 2017). Since health sciences students will engage in patient education, they should have good knowledge of diabetes management. Knowledge can form a basis for the adoption of good health-related practices. It will improve awareness and mind-set towards lifestyle-related illnesses, thus improving the quality of life. Therefore, this study was done to assess the level of knowledge and attitude of Diabetes Mellitus Type 2 among health sciences students. Then to identify the relationship between knowledge and attitude of Diabetes Mellitus Type 2 among health sciences students.

\subsection{Literature Review}

Diabetes Mellitus Type 2 is the most common form of diabetes which affects over $90 \%$ of the world's diabetic population (Valliyot, Sreedharan \& Muttappallymyalil, 2013). Prevalence of diabetes mellitus in Malaysia has been steadily increasing over the last two decades and is presently at a high level of almost $18 \%$. The sudden increase and current high prevalence of obesity and overweight in the state impacted nearly 50 percent of adults and 30 percent of school children for both developed and developing countries in all parts of the country (Tee \& Yap, 2017). Diabetes had been reported to cause complications such as long-term injury, organ dysfunction, and failures mainly to the eyes, heart, kidneys, nerves, and blood vessels (Qamar et al., 2017). A study was carried out by Al-Sarayra and Khalidi (2012) in Al-Baqa Applied University in Jordan found that there is poor knowledge and lack of awareness of certain aspects of diabetes amongst college students even though the college consists of many scientific and administrative departments and specialties.

Knowledge about diabetes mellitus is still at a minimal level in most of the college students, where they do not even know about the signs and symptoms of this illness and its complications (Premkumar, 2018). Good knowledge of diabetes mellitus will improve attitude and practice towards diabetes mellitus through a better educational program such as good healthy lifestyles (Ibrahim Abougalambou, Abaalkhail \& Abaugalambou, 2019). Adequate knowledge and attitude can reduce the complications and as a preventive measure towards diabetes mellitus (Wajid, Al-Arifi, Babelghaith et al., 2018). Kassahun and Mekonen (2017) stated that being knowledgeable about diabetes possesses a better attitude towards diabetes contrary to those who are not knowledgeable. Mgbahurike, Onwusah, and Amadi (2017) concluded that poor knowledge or deficiency of understanding of diabetes mellitus could be attributed to poor attitude such as diabetes mellitus is curable and regards to its complications and severity. Better knowledge of diabetes mellitus with good attitude and practices can be helpful in management for diabetes mellitus such seek for proper treatment and care on the complications of diabetes mellitus (Herath, Weerasinghe, Dias et al., 2017). However, regardless of overall great knowledge of Diabetic Mellitus, there were certain areas of deficiency that can be seen among the participants where serious levels of inadequacy in knowledge regarding complications and control of Diabetic Mellitus (Khamaiseh \& Alshloul, 2019). Herath et al. (2017) stated that having a better knowledge of diabetes did not translate into good practices due to poor involvement with any preventive measure.

\subsection{Methodology}

\subsection{Study design}

This research was a cross-sectional study conducted among students at the Faculty of Health Sciences of UiTM Puncak Alam.

\subsection{Sample}

Purposive sampling was used for this study with a sample size of 400 . The questionnaire was distributed among full-time degree and diploma students. The inclusion criteria for this study were the respondents must be health sciences and full-time students. The exclusion criteria of this study were respondents who are sick, on leave, and already participated in the pilot study.

\subsection{Instruments}

3.3.1 Diabetes Knowledge Questionnaire 24

Open access questionnaire adapted from Diabetes Knowledge Questionnaire-24 (DKQ-24) by Qamar et al. (2017). The questionnaire consists of 24 questions. Each question comprises the option "yes," "no," and "I don't know" that requires respondents to put a tick on the applicable column. Each correct answer was given the "1" mark while the "0" mark for the wrong and don't know the answer. The total score is categorized into three-level indicated by poor (0-8), moderate (9-16), and good (17-24). Higher scores represented more levels of knowledge about diabetes. A pilot study was conducted to test the validity and reliability of the questionnaire.

\subsubsection{Attitude towards Diabetes Mellitus}

The questionnaire was adapted from Redhwan, Osman, Ismail et al. (2017). The questionnaire consists of 9 questions. This questionnaire also use Likert scale with each question comprises the option "strongly disagree", "disagree", "do not know", "agree" and "strongly agree" that requires respondents to put a tick on the applicable column. Respondents were required to answer the questions from item 1 until 9 and tick the answer that describes their attitude towards diabetes. For "strongly disagree", marks were given as 1 , "disagree" as 2, "do not know" as 3, "agree" as 4, and "strongly agree" was given as 5. The minimum scores on the Likert scale indicate an unfavorable attitude, while the maximum scores indicate a positive attitude towards Diabetes Mellitus Type 2. 
3.3.3 Validity and Reliability for Diabetes Knowledge Questionnaire 24 and Attitude towards Diabetes Mellitus questionnaire.

The translation of the questionnaire was done by the researcher. Then the questionnaire was sent to four experts in diabetic management for comments. After that, the correction was done and sent back to the experts a second time for confirmation. Then face validation was done by 10 students. Students were asked to comment on the questionnaire. Base on their feedback, the modification of the questionnaire was done. Then a pilot study was done, involving 40 students from a group of health sciences, later they are excluded from involving in a real study. The data were analyzed using the Statistical Package for Social Sciences (SPSS) version 25. The Cronbach's alpha obtained were; Diabetes Knowledge Questionnaire $\alpha=0.700$ and attitude towards diabetes $\alpha=0.765$.

\subsection{Procedures}

The data was collected after approval from the Research Ethics Committee UiTM with reference no REC/577/19. Before the distribution of research instruments, a brief explanation of the research was given, and informed consent was acquired. The respondents were informed that they have the right to refuse from taking part in this study. The respondents answer the questionnaires within 20 to 30 minutes and the questionnaire was collected immediately by the researcher.

\subsection{Data Analysis}

Data were analyzed using SPSS version 25.0. Descriptive statistics were used to determine the level of knowledge and attitudes on Diabetes Mellitus Type 2 among health sciences students. Pearson's Correlation test was used to determine the relationship between knowledge and attitudes on Diabetes Mellitus Type 2 among health sciences students. A significant level was set at 0.05 .

\subsection{Result}

\subsection{Demographic data}

Table 1. Demographic data of respondent $(\mathrm{N}=400)$

\begin{tabular}{ccc}
\hline Variables & Categories & $\mathbf{N}(\%)$ \\
\hline Gender & Male & $56(14)$ \\
& Female & $344(86)$ \\
Course & Nursing & $50(12.5)$ \\
& Optometry & $50(12.5)$ \\
& Medical Imaging & $50(12.5)$ \\
Occupational Therapy & $50(12.5)$ \\
Physiotherapy & $50(12.5)$ \\
& Medical Laboratory and Technology & $50(12.5)$ \\
& Nutrition and Dietetics & $50(12.5)$ \\
& Environmental Health and Safety & $50(12.5)$ \\
& & $50(12.5)$ \\
Education & Degree & $392(98)$ \\
& Diploma & $8(2)$ \\
Years of study & Third-year & $218(54.5)$ \\
& Fourth-year & $182(45.5)$ \\
Family history & Yes & $209(52.3)$ \\
& No & $191(47.8)$ \\
\hline
\end{tabular}

Table 1 shows the descriptive analysis of the demographic data of this study. The majority of the respondents were females, comprising $344(86 \%)$. Most of the respondents were degree students with 392 respondents $(98 \%)$. The majority of the respondent was from thirdyear students $218(54.5 \%)$. A total of 209 respondents $(52.3 \%)$ stated that they have a family history of diabetes mellitus.

\subsection{Knowledge of Diabetes Mellitus Type 2 among Health Sciences Students}

Table 2. General Knowledge of Diabetic Mellitus ( $N=400)$

\begin{tabular}{clc}
\hline No. & \multicolumn{1}{c}{ General Knowledge of Diabetic Mellitus } & $\mathrm{N}(\%)$ \\
\hline 1. & Eating too much sugar and other sweet foods are a cause of diabetes. & $7(1.8)$ \\
2. & The usual cause of diabetes is lack of effective insulin in the body. & $364(91.0)$ \\
3. & Diabetes is caused by failure of the kidneys to keep sugar out of the urine. & $190(47.5)$ \\
4. & Kidneys produce insulin. & $305(76.3)$ \\
5. & In untreated diabetic, the amount of sugar in the blood usually increases. & $377(94.3)$ \\
6. & If I am diabetic, my children have higher chance of being diabetic. & $352(88.0)$ \\
7. & Diabetes can be cured. & $229(57.3)$ \\
8. & A fasting blood sugar level of $11.7 \mu$ mol/L (210mg/dL) is too high. & $265(66.3)$ \\
9. & The best way to check my diabetes is by testing my urine. & $260(65.5)$ \\
10. & Regular exercise will increase the need of insulin or other diabetic medication.
\end{tabular}




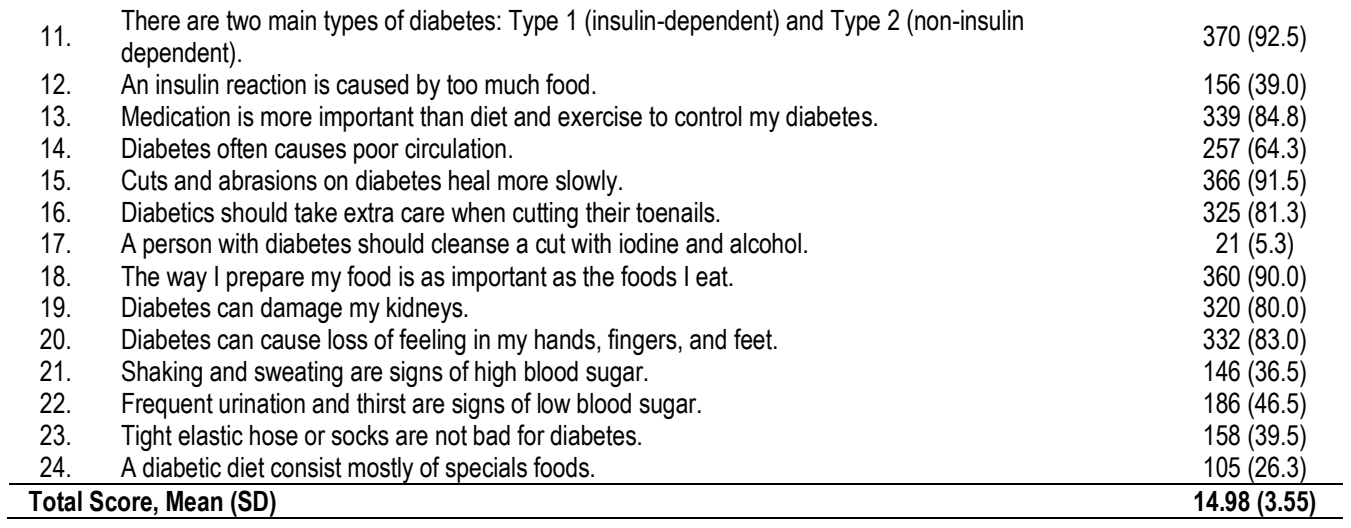

Table 2 shows the correct answers of respondents on the Diabetes Knowledge Questionnaire. The mean score ( $\pm S D)$ of correct DKQ answers was $14.98 \pm 3.55$ with a range of 5 to 22 with a median score of 15 , which suggests a moderate level of knowledge. The majority of respondents knew that there are different types of diabetes, which are Type 1 and Type 2, $n=370(92.5 \%)$. The respondents were aware that if diabetes is left untreated can lead to an increased amount of sugar in the blood $n=377(94.3 \%)$. The questions least frequently answered correctly were "eating too much sugar and other sweet foods are a cause of diabetes" $n=7(1.8 \%)$.

\subsection{Level of diabetes knowledge}

Table 3. Level of Diabetes Knowledge ( $\mathrm{N}=400)$

\begin{tabular}{cccc}
\hline Knowledge category & Score & Frequency $(\mathrm{n})$ & Percentage $(\%)$ \\
\hline Poor & $(0-8)$ & 19 & 4.8 \\
Moderate & $(9-16)$ & 234 & 58.5 \\
Good & $(17-24)$ & 147 & 36.8 \\
\hline
\end{tabular}

Table 3 shows the descriptive analysis of the level of diabetes knowledge. More than half of the respondents (58.5\%) scored moderate knowledge, while $36.8 \%$ of respondents obtained good knowledge.

\subsection{Attitude of Health Sciences Students towards Diabetes Mellitus Type 2}

Table 4. Attitude towards Diabetes Mellitus ( $\mathrm{N}=400)$

\begin{tabular}{|c|c|c|c|c|c|}
\hline \multirow[t]{2}{*}{ Attitude } & \multicolumn{5}{|c|}{ Frequency (\%) } \\
\hline & Strongly disagree & Disagree & Do not know & Agree & Strongly agree \\
\hline Diabetes mellitus is preventable & $18(4.5)$ & $12(3.0)$ & $23(5.8)$ & $160(40.0)$ & $187(46.8)$ \\
\hline Diabetes mellitus is treatable & $41(10.3)$ & $75(18.8)$ & $89(22.3)$ & $124(31.0)$ & $71(17.8)$ \\
\hline $\begin{array}{l}\text { Regular exercise helps controlling } \\
\text { diabetes }\end{array}$ & $8(2.0)$ & $0(0)$ & $42(10.5)$ & $199(49.8)$ & $151(37.8)$ \\
\hline $\begin{array}{l}\text { Following a controlled and planned diet } \\
\text { will help in controlling progression of } \\
\text { diabetes mellitus }\end{array}$ & $8(2.0)$ & $0(0)$ & $7(1.8)$ & $170(42.5)$ & $215(53.8)$ \\
\hline $\begin{array}{l}\text { Regular checking of blood sugar level } \\
\text { is important in diabetic patient }\end{array}$ & $8(2.0)$ & $1(0.3)$ & $2(0.5)$ & $143(35.8)$ & $246(61.5)$ \\
\hline $\begin{array}{l}\text { Diabetic patients should keep in touch } \\
\text { with their physician }\end{array}$ & $6(1.5)$ & $5(1.3)$ & $15(3.8)$ & $179(44.8)$ & $195(48.8)$ \\
\hline $\begin{array}{l}\text { It is necessary for diabetic patient to } \\
\text { take medication properly and regularly }\end{array}$ & $8(2.0)$ & $4(1.0)$ & $24(6.0)$ & $171(42.8)$ & $193(48.8)$ \\
\hline $\begin{array}{l}\text { Missing the doses of diabetic } \\
\text { medication will have a negative effect } \\
\text { on the disease control }\end{array}$ & $8(2.0)$ & $15(3.8)$ & $83(20.8)$ & $170(42.5)$ & $124(31.0)$ \\
\hline $\begin{array}{l}\text { Smoking exacerbates vascular } \\
\text { complications due to diabetes }\end{array}$ & $12(3.0)$ & $4(1.0)$ & $81(20.3)$ & $147(36.8)$ & $156(39.0)$ \\
\hline Total Score, Mean (SD) & & & & & $37.47(5.17)$ \\
\hline
\end{tabular}

Table 4 shows the descriptive analysis of attitude towards diabetes mellitus. The mean score $( \pm S D)$ was $37.47 \pm 5.17$ with a range of 9 to 45 with a median score of 38 , which suggests a positive level of attitude for participating respondents. Only n=124 (31.0\%) and n=71 $(17.8 \%)$ of the respondents were agreed and strongly agree that diabetes mellitus was treatable. Controlled and planned diet, respondents agreed that it can help in controlling the progression of diabetes mellitus $n=170(42.5 \%)$ agreed and $n=215(53.8 \%)$ strongly agreed. Respondents showed a positive result on attitude about regular checking blood sugar level with $n=143(35.8 \%)$ agreed and $n=246(61.5 \%)$ strongly agreed. 
4.5 Relationship between Knowledge and Attitude of Diabetes Mellitus Type 2 among Health Sciences Students

Table 5 shows a result of the relationship between knowledge and attitude of diabetes mellitus among health sciences students. The correlation between knowledge score and attitude score is significant which is $p$-value $<0.001$. There is a fair and positive correlation between knowledge and attitude toward diabetes mellitus among health sciences students.

\begin{tabular}{|c|c|c|}
\hline \multirow[b]{3}{*}{ Attitude score } & \multicolumn{2}{|c|}{ Knowledge Score } \\
\hline & $r$ & $p$-value \\
\hline & $0.210^{*}$ & $<0.001$ \\
\hline
\end{tabular}

\subsection{Discussion}

\subsection{Knowledge of Diabetes Mellitus Type 2 among Health Sciences Students}

This study showed a good result regarding the level of knowledge among health sciences students. The findings of this study indicated that half of the respondents scored a good and moderate knowledge of Diabetes Mellitus Type 2. Consistent with the previous studies, the knowledge of the respondents would be satisfying due to the reason that the respondents were in the health sciences field. Similar to Khamaiseh and Alshloul (2019) report that the respondents showed a high level of knowledge in answering the questions regarding diabetes since the respondents were health sciences, university students. Students in science-related courses showed better knowledge than those in arts-related courses (Mgbahurike, Onwusah, \& Amadi, 2017). The high level of knowledge among health sciences students may be because the students are more educated than the general population, so health science students can score better (Khamaiseh \& Alshloul, 2019). Other than that, it may be due to health science students already experience dealing with a diabetic patient during clinical placement in a hospital. During clinical students will face a lot of patients with a variety of conditions which allows them to experience the management of a common disease. Redhwan et al. (2017) also report that the majority of respondents with a high level of education showed a greater level of knowledge about diabetes mellitus regarding the symptoms, complications, prevention, and treatment of the disease. However, in this study, the questions least frequently answered correctly were "eating too much sugar and other sweet foods are a cause of diabetes" (1.8\%) and a diabetic diet consist mostly of specials foods (26.3\%). Kharono et al. (2017) also found that persis avoiding sweet foods was not as highly regarded, with only $51.3 \%$ of respondents reporting it as a method of preventing the disease. Similar to Shilpashree and Namita (2018), a less satisfactory result was reported where the nursing students have poor knowledge in managing patients with diabetes including the diet and symptoms of diabetes. While a study from Požar and Simin (2019), states that most of the nursing students have a piece of good knowledge about diabetes but they lack knowledge about diabetic nutrition. This show that student did not understand about nutrition for diabetic patient. An extra hour for diabetic nutrition education should be done to the health science students since as a healthcare team they need to educate the community later about diabetic management. Diabetic patients usually acquire their knowledge about diabetic self-management from various resources, thus the healthcare team needs to have a piece of good knowledge for patient education.

\subsection{Attitude of Health Sciences Students towards Diabetes Mellitus Type 2}

The findings of this study indicated that the majority of respondents had a positive attitude towards Diabetes Mellitus Type $2.98 \%$ of respondents scored more than $50 \%$ of the total score. Similar to Redhwan et al. (2017) report that $97.5 \%$ of respondents scored more than 50 percent of the total score. In contrast with Herath et al. (2017), 88\% of the respondents portrayed a poor attitude towards diabetes. This is maybe due to the study was done among the public whereas this study was done among health sciences students. Students in the health sciences will be exposed to disease management. Besides that, the respondent from this study was from thirdand fourth-year students. These students were already exposed to the clinical area since students already do the clinical session in the hospital, so they can have a good score in attitude toward diabetic Mellitus. Besides that, about half $(52.3 \%)$ of our respondents have a family history with diabetes, this situation will give the respondents early exposure to diabetic management. Having a family history of diabetes was found that will influence the students' perception and knowledge of diabetes (Al-Mahroogi, Al-Hadhrami, Al-Amri, et al., 2013).

\subsection{The Relationship between Knowledge and Attitude of Diabetes Mellitus Type 2 among Health Sciences Students}

This study found that there was a significant correlation between the knowledge and attitude of respondents. This finding is consistent with research conducted by Redhwan et al. (2017) reported that a weak and positive correlation between knowledge and attitude of respondents towards diabetes mellitus. This study shows that knowledge is the most important factor that leads to a good attitude toward diabetic Mellitus. Mgbahurike, Onwusah, and Amadi (2017) report that poor knowledge of diabetes mellitus could be attributed to poor attitude. A high degree of understanding of diabetes mellitus had shown a positive attitude towards disease prevention (Kharono et al., 2017). Studies are done among the public also report that there was a positive association between knowledge and good attitude among respondents (Fatema, Hossain, Natasha et al., 2017). This shows that when respondents know diabetic Mellitus, they will have a positive attitude even though the respondents are not from the health science field. This could relate that knowledge is the fundamental weapon in the fight against diabetic Mellitus. Since patients with diabetic Mellitus have impairment in their quality of life (Porojan et al., (2012), it 
is important to prepare the health sciences student with the right knowledge and attitude toward diabetic Mellitus as they will serve as a facilitator to educate patient about diabetic management later.

\subsection{Conclusion and Recommendation}

In conclusion, this study showed that most of the respondents had a good and moderate level of knowledge in diabetes mellitus and displays a positive attitude towards diabetes mellitus. This finding shows that increased knowledge is related to positive attitudes. Although the majority of the respondents had adequate knowledge of diabetes, there is still some room for improvement as few respondents score poor knowledge on various aspects of diabetes, especially in nutrition and management of diabetes. Future research can look at a comparison between health sciences and non-health sciences students to look at the area that can be improved to prepare a young generation that aware of diabetic Mellitus. There is also a need for regular appraisal of health care students' knowledge through conducting an educational training workshop at initial stages. Awareness campaigns about diabetic Mellitus should be done among university students, such as making a poster, a series of talks to enhance their knowledge since health sciences students were very closed to the public.

\section{Acknowledgment}

Our appreciation goes to the Universiti Teknologi MARA Puncak Alam, Centre for Nursing Studies, Faculty of Health Sciences, and all participants in this study.

\section{Paper Contribution to Related Field of Study}

This paper contributes to the health and wellbeing field of study.

\section{References}

Al-Mahrooqi, B., Al-Hadhrami, R., Al-Amri, A., Al-Tamimi, S., Al-Shidhani, A., Al-Lawati, H., Al-lsmaili, A., Al-Hooti, K., and Al-Ghafri, T. (2013). Self-reported knowledge of diabetes among high school students in Al-Amerat and Quriyat, Muscat Governate, Oman. Sultan Qaboos Univ Med J, 13(3), 392-398.

Al-Sarayra, L., \& Khalidi, R. S. (2012). Awareness and knowledge about diabetes mellitus among students at al-baqa' applied university. Pakistan Journal of Nutrition, 11(11), 1023-1028.

Begic, E., Arnautovic, A., \& Masic, I. (2016). Assessment of Risk Factors for Diabetes Mellitus Type 2. Materia Socio Medica, $28(3)$, 187. https://doi.org/10.5455/msm.2016.28.187-190

Cotton, M. (2019). How insulin works. Retrieved March 30, 2019, from Kaiser Foundation Health Plan of Washington website:

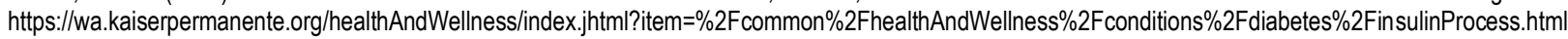

Dabelea, D., DeGroat, J., Sorrelman, C., Glass, M., Percy, C. A., Avery, C., ... Hamman, R. F. (2009). Diabetes in Navajo Youth: Prevalence, incidence, and clinical characteristics: the SEARCH for Diabetes in Youth Study. Diabetes Care, 32(Supplement_2), S141-S147. https://doi.org/10.2337/dc09-s206

Fatema, K., Hossain, S., Natasha, K., Chowdhury, H. A., Akter, J., Khan, T., \& Ali, L. (2017). Knowledge attitude and practice regarding diabetes mellitus among Nondiabetic and diabetic study participants in Bangladesh. BMC Public Health, 17(1), 1-10. https://doi.org/10.1186/s12889-017-4285-9

Herath, H. M. M., Weerasinghe, N. P., Dias, H., \& Weerarathna, T. P. (2017). Knowledge, attitude and practice related to diabetes mellitus among the general public in Galle district in Southern Sri Lanka: a pilot study. BMC Public Health, 17(1), 535. https://doi.org/10.1186/s12889-017-4459-5

Ibrahim Abougalambou, S. S., AbaAlkhail, H., \& Abougalambou, A. S. (2019). The knowledge, attitude and practice among diabetic patient in central region of Saudi Arabia. Diabetes \& Metabolic Syndrome, 13(5), 2975-2981. https://doi.org/10.1016/j.dsx.2019.07.049

Kassahun, C. W., \& Mekonen, A. G. (2017). Knowledge, attitude, practices and their associated factors towards diabetes mellitus among non diabetes community members of Bale Zone administrative towns, South East Ethiopia. A cross-sectional study. PLOS ONE, 12(2), e0170040. https://doi.org/10.1371/journal.pone.0170040

Khamaiseh, A. M., \& Alshloul, M. N. (2019). Diabetes knowledge among health sciences students in Saudi Arabia and Jordan. Jordan Medical Journal, 53(1), 23-35.

Khan, N., Gomathi, K. G., Shehnaz, S. I., \& Muttappallymyalil, J. (2012a). Diabetes mellitus-related knowledge among university students in Ajman, United Arab Emirates. Sultan Qaboos University Medical Journal. https://doi.org/10.12816/0003144

Kharono, B., Nabisere, R., Kiddu Persis, N., Nakakeeto, J., Openy, A., \& Bakeera Kitaka, S. (2017). Knowledge, Attitudes, and Perceived Risks Related to Diabetes Mellitus Among University Students in Uganda: A Cross-Sectional Study. East African Health Research Journal, 1(2), 105-112. https://doi.org/10.24248/eahrj.v1i2.556

Mgbahurike, A. A., Onwusah, D. O., \& Amadi, D. O. (2017). Knowledge Attitude And Perception Of Diabetes Mellitus Among Students Of University Of Port Harcourt, Rivers State, South-South Zone Nigeria. World Journal of Pharmaceutical Research, (June), 92-107. https://doi.org/10.20959/wjpr201710-9388

Mongiello, L. L., Freudenberg, N., Jones, H., \& Spark, A. (2016). Many college students underestimate diabetes risk. Journal of Allied Health. 
Porojan, M., Poantă, L., \& Dumitraşcu, D. L. (2012). Assessing health related quality of life in diabetic patients. Romanian journal of internal medicine = Revue roumaine de medecine interne, 50(1), 27-31.

Požar, H., Jn, P., \& Simin, D. (2019). Diabetes and Education - Knowledge Level about Diabetes Management in Nurses Student. Nursing \& Healthcare International Journal, 3(1), 1-9. https://doi.org/10.23880/nhij-16000171

Premkumar, D. (2018). Awareness of diabetes mellitus and its complications among students in a Malaysian university. Journal of Medicine, Radiology, Pathology and Surgery, 5(4), 1-4. https://doi.org/10.15713/ins.jmrps.134

Qamar, M., Rashid, R., Ahmad, S., Shaikh, F. A., \& Ismail, N. E. (2017). Awareness Of Diabetes Mellitus Among General Public In Shah Alam, Malaysia: A CrossSectional Study. Asian Journal of Pharmaceutical and Clinical Research, 10(9), 192. https://doi.org/10.22159/ajpcr.2017.v10i9.17747

Redhwan, A. A.-N., Osman, M. T., Ismail, N., Ismail, Z., Aini, N., Noor, M., ... Selamat, B. (2017). Diabetes Mellitus among Selected Malaysian Population: A CrossSectional Study. International Journal of Medical Research \& Health Sciences, 6(4), 1-11. Retrieved from www.ijmrhs.com

Shilpashree, Y., \& Namitha, D. (2018). Assessment of diabetes knowledge amongst nursing students. International Journal of Appl led Research 2018;, 4(8), 225-228.

Suzana, S., Kee, C., Jamaludin, A., Noor Safiza, M., Khor, G., Jamaiyah, H., ... Ahmad Fauzi, Y. (2012). The Third National Health and Morbidity Survey. Asia Pacific Journal of Public Health, 24(2), 318-329. https://doi.org/10.1177/1010539510380736

Tee, E.-S., \& Yap, R. W. K. (2017). Type 2 diabetes mellitus in Malaysia: current trends and risk factors. European Journal of Clinical Nutrition, 71(7), 844-849. https://doi.org/10.1038/ejcn.2017.44

Valliyot, B., Sreedharan, J., \& Muttappallymyalil, J. (2013). Risk Factors Of Type 2 Diabetes Mellitus In The Rural Population Of North Kerala , India : A Case Control Study. 2030(1), 33-40.

Wajid, S., Al-Arifi, M. N., Babelghaith, S. D., Naqvi, A. A., Althagfan, S. S., \& Mahmoud, M. A. (2018). Pharmacy students' knowledge and attitudes towards diabetes: A cross-sectional study. Biomedical Research (India), 29(19), 3638-3642. https://doi.org/10.4066/biomedicalresearch.29-18-1074 